на каждом уровне: на начальном уровне делается акцент на «Pronunciación de los sonidos» (произношение звуков), а на более высоком уровне это уже «Realización fonética de los fonemas españoles» (фонетическая реализация фонем, другими словами, фонологический уровень). Содержание начального уровня базируется на производстве вокальных и консонантных звуков. Средний уровень (intermedio) предполагает идентификацию и производство звуковых вариантов, иными словами, овладение всем многообразием аллофонического содержания с учётом контекстуальных и позиционных вариантов. При этом интонация должна преподаваться с начального уровня, базовые знания интонационных особенностей испанского языка включают повествование, вопросительную интонацию и восклицание. Уровень начальный и средний предполагают также знакомство с просодикой и ритмикой испанской фразы. Различие методов обучения фонетическим навыкам очевидно, и сообразно каждому этапу обучения необходимо использовать соответствующие данному уровню методики.

Таким образом, большое значение в исследованиях по теоретической и практической фонетике имеет разработка методов и дидактических материалов для наиболее эффективного преподавания и изучения фонетики и фонологии испанского языка.

\title{
Лuтература
}

1. M.B. Fontanella de Weinberg, M. B., La lengua española fuera de España. - Buenos Aires, Editorial Paidós, 1976, 188 págs.

2. Hernández Alonso, (2001): “QQué norma enseñar?”en Actas electrónicas del II Congreso Internacional de la Lengua Española, "El español en la Sociedad de la Información”, Valladolid, 16-19. URL: http://cvc.cervantes.es/obref/congresos/valladolid/ponencias/unidad_diversidad_ del_espa\%C3\%B1ol/1_la\%20norma_hispanica/hernandez_c.htm

3. García Mouton P., Lenguas y dialectos de España. - Madrid: Arco Libros, 1994 (Cuadernos de Lengua Es $\neg$ pañola). -235 p.

4. Navarro Tomás T., Manual de la pronunciación española. - Madrid: Consejo Superior de Investigaciones Científicas, 1990. - $326 \mathrm{p}$.

5. Real Academia Española, Esbozo de una nueva gramática de la lengua española. - Madrid: Espasa-Calpe, 1991, 525 p.

\section{ю.в. Өливчикова}

\section{Костюм как символ политического протеста в испанском газетно-публицистическом дискурсе}

В статье рассматривается когнитивный механизм формирования общественного мнения через описание костюма политика в СМИ. Автор, сравнивая описания внешнего вида представителей правых и левых партий, выделяет и исследует функцию протеста изначально нейтральной вестиментарной лексики. Одежда, приобретая в газетно-публицистическом дискурсе политическую коннотацию, становится эффективным способом манипулятивного воздействия на сознание избирателя.

Ключевые слова: манипуляция, газетно-публицистический дискурс, вестиментарная лексика. 


\section{Yu. Slivchikova \\ CLOTHING AS A SYMBOL OF THE POLITICAL PROTEST IN SPANISH POLITICAL AND JOURNALISTIC DISCOURSE}

The article considers the costume description as an efficient political tool. The study sets out to show by comparing the clothing description of the representatives of the opposing parties that the vestimentary elements obtain new meanings affecting the image of the person that is nothing else but the way of the public control.

Key words: political discourse, clothing, manipulation.

С древних времён одежда являлась отражением различия сословий, общественных классов, то есть несла в себе функции знака. Вестиментарная система образовывала кодовую систему, нарушение которой приводило к социальному конфликту, что нередко становилось основой для сюжетной линии в мировой литературе. После Французской революции тенденция к демократизации общества привела к единообразию в костюме, когда одежда стала в первую очередь отвечать требованиям равенства и труда. Однако разделение социальных классов не пропало, хотя и возникла определённая трудность маркирования, поскольку произошёл резкий подъём среднего класса. С этого момента различительные функции костюма на себя взяла деталь: узел галстука, ткань сорочки, пуговицы, цвет. Век двадцатый, окончательно размыв границы между сословиями, всё же оставил различия в социальных статусах, основывающихся на экономическом показателе, и объявил три основных признака значимыми в одежде: качество, цена и марка. В остальной части признаков одежда утратила свою различительную способность, что отчасти поставило в тупик политическую элиту. Ушли в прошлое времена, когда бургиньоны носили корнет справа, а арманьяки - слева и тем самым очевидно демонстрировали свои политические пристрастия. Теперь политиков соперничающих партий сложно отличить друг от друга по внешнему виду. Любопытно, что исчезнувшие внешние различия обнажили ещё более нивелированную разницу между идеологиями оппонентов, чем особо недовольно современное испанское общество. Будто заранее договорившись, 5 мая 2010 года во дворец Монклоа прибыли с целью обсудить ситуацию в Греции премьер-министр социалистического правительства Хосе Луис Родригес Сапатеро и лидер оппозиции Мариано Рахой, оба в тёмно-синих костюмах, белых рубашках и полосатых галстуках в тон.

Партии правых остались при этом в более выгодном положении, поскольку приверженность традициям и классическому стилю, породившему норму стиля делового, принятого за основу протокольного костюма, в их случае не противоречили никоим образом их политическим убеждениям и курсу. Однако левые оказались в затруднительном положении. Как отличаться от своих оппонентов, если классический костюм является нормой в обществе? Для этого необходимо обратиться к истории.

17 октября 1945 года в Буэнос-Айресе стояла страшная жара. Рабочие, собравшиеся на манифестацию, протестуя против заключения под стражу Хуана Перона, вынуждены были снять рубашки, находясь под палящим солнцем. Тогда противники Перона стали презрительно называть сторонников хустисианализма безрубашечниками (Descamisados). Но прошло совсем немного времени, и вот уже Ева Перон обратилась к «своим любимым «дескамисадос» с трибуны, превратив это определение в гордость трудового народа. Задолго до этого в 1862 году Виктор Гюго описал в своём знаменитом романе «Униженные и оскорблённые» историю безрубашечников. Так гордо назвали себя политически активные представители бедноты в эпоху Испанской революции 1820-1823 годов, которые составляли левое крыло организации комунерос. Так их стали называть и испанские монархисты, сторонники Фернандо VII. Такое название в их устах, однако, содержало в себе элемент презрения (peyorativo у despectivo), который в своё время вкладывали консервативные французы в 1789 году в прозвище «sans culottes». Санкюлотами называли революционно настроенных бедняков в Париже во время Великой Французской революции, поскольку они не носили коротких обтягивающих штанов (кюлотов), как это делали представители богатых 
сословий, а были одеты в длинные брюки. Любопытно, что выше описанные примеры строятся не на оппозиции определённых элементов в одежде, а на противопоставлении наличия одежды и её отсутствия. Причём это отсутствие рубашки или брюк расценивается современниками по-разному, в зависимости от их партийной принадлежности. Мы замечаем, как обычная одежда приобретает смысл, который не покрывается её применением [1]. Она приобретает политическую коннотацию в зависимости от точки зрения и контекста. Одежда подсознательно неразрывно соединяется с человеком, и происходит взаимное перетекание смысла. Богатые люди носят кюлоты, значит кюлоты - это символ буржуазии и достатка, и тогда любой человек без кюлотов - революционер, и наоборот. Обычные брюки становятся символом целого сословия, а их отсутствие символом революционного протеста. Но если рассмотренные нами примеры можно назвать исторически обусловленными, то есть не являющимися символом, скажем, рукотворным, появившись в силу бытовых обстоятельств, то существуют примеры вестиментарных символов, созданных сознательно. Так, например, женская часть группы испанских писателей, художников и музыкантов, объединённых названием «Поколение 27 года» во главе с Маргаритой Нелькен выступили против ношения головных уборов в общественных местах Мадрида, заявив таким образом о правах и свободах женщин. Отсутствие головного убора стало символом феминистической борьбы за независимость женщин. А ведь полвека назад жительницы Мадрида протестовали как раз наоборот, с помощью головного убора, а именно мантильи. Её они превратили в символ своего недовольства правлением Амадео де Савойа и его супруги Марии Виктории (18701873). Своё неприятие лично к королевской чете и заморским традициям знатные дамы выражали, расхаживая по улице в мантилье с гребнем вместо шляпки. Факт, который вошёл в историю под названием «Заговор мантилий» («La conspiración de las mantillas»).

Подобные примеры политического протеста с помощью костюма мы встречаем и в наши дни. Возьмём отрывок из статьи в «El Mundo», описывающий свадьбу наследного принца Испании Филиппа и доньи Летисии в 2004 году.

«Miguel Bosé ha llegado junto a la soprano Ainoha Arteta. Con un chaqué impecable y chaleco granate» [2]. - Мигель Босэ прибыл в сопровождении Аиноы Артета в безупречной визитке и гранатовом жилете.

Данное описание обладает имплицитным мирским означаемым. Речь в статье идёт о королевской свадьбе, и посвящённый круг читателей знаком с её Протоколом. В частности, мужчины должны быть одеты в особый род сюртука. Наблюдая за одеянием мужчин на свадьбах такого уровня, мы действительно заметим, что все они одеты в визитки. Данная знаковая система располагается в реальности, и можно не знать языка или быть глухонемым, но, посетив королевскую свадьбу, с очевидностью понять это. То есть перед нами эквивалентность реального мира и реальной вещи, иными словами, реальный вестиментарный код. Однако читая описание одежды в газете, мы не видим её перед собой, она нам представляется в виде совокупности элементов испанского языка, так что язык образует вторую систему, которую мы назовём «словесным вестиментарным кодом или терминологической системой, поскольку она просто денотирует реальность мира и одежды в форме номенклатуры» [3]. Во второй системе фраза, включающая в себя систему букв, станет означающим означаемого-пропозиции, включающего знак реального вестиментарного кода. Но с какой целью нам дана данная эквивалентность? Очевидно, что она приводится, потому что в целом знаменует собой Протокол, становясь означающим для нового означаемого. Протокол тем самым коннотатирует знаковое отношение между кроем сюртука и родом и рангом мероприятия, которое денотировалось во второй системе. Самим фактом упоминания терминологическое высказывание означает Протокол. Но приглядевшись внимательно к высказываю о Протоколе, взятому из газетной статьи, мы можем заметить ещё один интересный факт. Газета, желая создать у читателя представление о мире, даже навязать ему своё видение, сформировать отношение к событиям или личностям, использует определённый набор языковых средств, тем самым образуя ещё одно коннотативное сообщение или последнюю, риторическую систему. Заметим, что у 
читателя нет времени анализировать данную структуру снизу, как это следовало бы делать. Он воспринимает её целиком сверху.

Сравним с описанием одеяния лидера Всеобщего союза трудящихся (UGT) в той же статье: «Cándido Méndez, sin chaqué, como había advertido». [4] - Кандидо Мендес - без визитки, как он и предупреждал. Кроме простого несоответствия Протоколу очевидно, что отсутствие визитки является демонстрацией идеологических соображений гостя и говорит о многом посвящённому читателю. Непосвящённому же читателю придётся объяснить, что таким образом лидер профсоюзов выразил своё отличие от присутствующих консерваторов и показал свою смелость и желание быть ближе и понятнее трудовому народу.

Иногда, правда, не только левые политики прибегают к вестиментарным уловкам, чтобы казаться ближе своему избирателю: «El primer ministro británico, David Cameron, ha descartado vestirse de chaqué para asistir a la boda del príncipe Guillermo y Kate Middleton el 29 de abril y optará, en cambio, por un traje de calle para desligarse de la imagen encopetada de su pasado, según indica The Daily Telegraph» [5]. - Премьер-министр Великобритании, Дэвид Кемерон, отказался надеть визитку на свадьбу принца Уильяма и Кейт Мидлтон 29 апреля и выбрал, напротив, повседневный костюм, чтобы откреститься от высокомерного образа в прошлом, как разъясняет «The Daily Telegraph». История уходит корнями в студенческое прошлое премьер-министра, который являлся членом Клуба Буллингтон в Оксфордском Университете, славящегося скандальными празднествами. Единожды появившаяся в прессе фотография юного Кемерона в смокинге с бабочкой и бокалом шампанского сильно подорвала его репутацию, что заставило его пересмотреть свою «костюмную политику». Однако на то, чтобы искоренить сформированный в сознании образ, как мы знаем, уходят годы.

Рассмотрим описание костюма министра экономики Аргентины Акселя Кисиллофа, которое мы находим в газете «El País»:

«Un año después, se le ve en la casa Rosada con pantalones vaqueros y chaqueta, con cuaderno y boli, rodeado de su equipo económico, gente del mismo porte juvenil, con chaqueta y sin corbata» [6]. - Через год мы встречаем его в Розовом доме в джинсах и пиджаке, с тетрадкой и ручкой. Он окружён своей командой экономистов, такими же молодыми людьми в пиджаках и без галстука.

В этом вестиментарном описании мы обнаруживаем очень популярный ныне среди политиков способ когнитивной эмпатии - отсутствие галстука. Галстук как атрибут делового общения имеет элемент официоза, отсутствие его, напротив, располагает к непринуждённому общению и расценивается как знак большего доверия собеседнику, желания пообщаться в дружеской обстановке. Без галстука политик становится ближе к народу, понятнее той его части, которая не носит его вовсе. Однако, с точки зрения консервативной части электората, отсутствие галстука является знаком легкомысленности, ветрености, ненадёжности. Наименования одежды в политическом дискурсе, а вслед за ним и в газетно-публицистическом, могут иметь различные вторичные значения в зависимости от направленности издания и идеологической принадлежности читателя. Для консерваторов слова «camiseta, jeans, jersey, sandalias, chándal, zapatillas deportivas, botas, cazadora» в контексте описания костюма политика могут приобретать значение «indigno, indecoroso, inmoral, insultante».

Американский драматург Артур Миллер в своей лекции о роли актерского мастерства в политике задался вопросом: за кого голосует избиратель, за реального ли человека или красивую картинку, созданную благодаря профессиональным советникам, костюму и многочисленным технологиям, призванным сформировать в восприятии народа идеального кандидата? К сожалению, приходится констатировать, что имидж играет большую роль. Приятный во всех отношениях образ способен «продать» избирателю не самую лучшую идею, идея же хорошая может с треском провалиться, если её не подержать должным имиджем. Хосе Мария Аснар, бывший председатель испанского правительства, всегда считался человеком серьёзным, сдержанным и консервативным, что было заметно не только по предпринятым им политическим мерам, но и по его причёске и усам. Однако 
тот факт, что ещё занимая свой пост, он не расставался с пёстрыми браслетами из ниток, а после своей отставки отрастил волосы, наводит на мысль о том, что всё же скорее это был хорошо продуманный образ, созданный специально для продвижения по политической карьерной лестнице. Или, к примеру, Фелипе Гонсалес, будучи лидером оппозиции в 70-х годах под влиянием движения рабочих и молодёжи одевался соответственно в вельветовые коричневые костюмы с модными заплатками на локтях, блистал бакенбардами и шикарной шевелюрой. Однако придя к власти, андалусский социалист сразу забыл о бунтарской эстетике и оделся в классический костюм с рубашкой и галстуком [7].

Что же важнее: имидж или идеи? Правильнее будет сказать, что они важны одинаково и должны соответствовать друг другу. Когда содержание и оболочка находятся в гармонии, одежда не вызывает больного интереса у электората. Поясним: ни внешность экс-президента испанского правительства Фелипе Гонсалеса, ни бывшего председателя правительства Каталонии Жорди Пужоля никогда не упоминались в СМИ, что оставляло место лишь обсуждению собственно их реформистской деятельности. Своим безупречным внешним видом славился и герой переходного периода Испании к демократии Адольфо Суарес, образ которого был настолько популярен, что ему стали даже подражать в причёске и одежде в 70-х годах прошлого века. Ни один из великих персонажей XX века не пренебрег таким важным составляющим образа, как политический костюм. От Гитлера до Кастро, включая Сталина, Муссолнини, Франко и Мао политики поддерживали свою идеологию сильной власти строгим военным мундиром, не оставлявшим места для дискуссий.

Однако, например, в 2009 году на портале «LibertadDigital» вышла статья под звучным названием-метафорой «Так Сапатеро утягивает пояс» («Así se aprieta Zapatero el cinturón»): «El pasado domingo en el mitin del PSOE en la plaza de Vista Alegre, Zapatero lució un cinturón de la firma Hermés, valorado en 500 euros. La misma cantidad que él dará para comprarse un coche, y con la que subsisten familias enteras de parados» [8]. - В прошлое воскресение на митинге Испанской социалистической рабочей партии на площади Виста Алегре Сапатеро появился, подпоясанный ремнём марки Hermés стоимостью 500 евро. Именно эту сумму он собирается субсидировать для покупки машины, и столько же получают целые семьи безработных в виде пособий. Несоответствие позиции политика, его реформистской деятельности и его внешнего вида разочаровывает избирателя. Если один из элементов костюма несёт в себе фальшь, то значит, и весь костюм является маскарадным, а выступление политика - ничем иным, как театрализованным представлением. Одна деталь способна разрушить весь образ, но и способна его создать и даже превратиться в символ политической борьбы.

Следует подчеркнуть, что в газетно-публицистическом дискурсе описание костюма политика используется для транслирования определенного образа с целью создания у читателя путем различных манипулятивных техник нужного автору статьи мнения или убеждения. Под манипуляцией мы вслед за профессором М.В. Ларионовой понимаем «особый вид психологического воздействия на сознание и поведение массовой аудитории, который осуществляется в скрытой форме с помощью различного рода дискурсивных, языковых и экстралингвистических приемов, создающих необходимый прагматический эффект. В результате подобного воздействия человек делает выбор, отличный от того, который мог бы сделать самостоятельно, при этом сохраняя уверенность, что действует в соответствии с собственными убеждениями, желаниями и намерениями» [9]. В нашем случае языковой прием заключается в использовании сложной структуры вестиментарного знака, которая преподносит коннотативное значение в виде денотативного и переносит свойства одежды на человека, заставляя читателя принять их за непреложную истину. Вестема, изначально нейтральная, в контексте газетно-публицистического дискурса обрастает дополнительными смыслами, сводящимися в сознании человека к ограниченному количеству концептов, обобщающих бытование костюма в обществе.

Таким образом, хотя правые партии имеют фору в политическом костюме, поскольку протоколом закреплены устоявшиеся традиции, которые и стараются хранить консерваторы, у левых есть возможность наглядно демонстрировать своё несогласие с существующим порядком вещей и свою яркую индивидуальность через элементы одежды. Костюм при 
этом обрастает дополнительными смыслами и приобретает различные прочтения не только в зависимости от контекста, но и в зависимости от политических взглядов избирателя. Элементы его или их отсутствие могут становиться яркими символами протеста, позволяя имплицитно передавать информацию в одном коммуникативном сообществе, создавая некую атмосферу сообщничества. Само несоответствие протоколу может уже трактоваться как протестное явление. Однако необходимо быть последовательным и, выбирая костюм, внимательно относиться к каждой его детали, не забывать о том, что костюм политика нередко используется для того или иного манипулятивного приёма. Роль костюма как убедительной формы утверждения политической позиции сложно переоценить.

\section{Лuтература}

1. Барт Р. Система Моды. Статьи по семиотике культуры. Пер. с фр., вступ. ст. и сост. С.Н. Зенкина. - М.: Изд-во им. Сабашниковых, 2004. - С. 418.

2. Bueno A., Marcos C. Boda Real. El Mundo. 22.05.2004. URL: http://www.elmundo.es/ especiales/2004/04/espana/bodareal/22m_envivo.html

3. Барт Р. Указ. соч. - С. 70.

4. Bueno A., Marcos C. Указ. соч.

5. Cameron será el primer jefe de Gobierno británico que acude a un enlace real sin chaqué. RevistaProtocolo.com. 18.04.2011. URL: http://www.revistaprotocolo.es/gente/gente/5769-cameronsera-el-primer-jefe-de-gobierno-britanico-que-acude-a-un-enlace-real-sin-frac.html

6. Peregil F. Kicillof, la cara guapa de la economía argentina. El País. 31.01.2014.

URL: http://elpais.com/elpais/2014/01/31/gente/1391191651_929422.html

7. Centeno P. Espejo de P, 32 Espejo de Marx.

8. Así se aprieta Zapatero el cinturón. Libertad Digital. 13.05.2009. URL: http://www. libertaddigital.com/sociedad/zapatero-no-se-aprieta-el-cinturon-1276359164/

9. Ларионова М.В. Испанский газетно-публицистический дискурс: искусство информации или мастерство манипуляции?: монография / Моск. гос. ин-т междунар. отношений (ун-т) МИД России, каф. испанского языка. - М.: МГИМО-Университет, 2015. С. 51.

\section{K.В. Урсул \\ Макрополе Presente в парадигме временной системы Indicativo [на материале современного испанского языка]}

Статья посвящена анализу функционирования форм Presente de Indicativo в структуре современного испанского языка. Подробно рассматривается семантика временной системы Indicativo в рамках функционально-семантического подхода, выделяются микрополя и семантические зоны, формирующие макрополе Presente.

Ключевые слова: семантические зона, макрополе, микрополе, ядро, функциональносемантическое поле. 